\title{
Polycyclic aromatic hydrocarbons and their nitrated derivatives associated with PM10 from Kraków city during heating season
}

\author{
Katarzyna Styszko ${ }^{1, a}$, Katarzyna Szramowiat ${ }^{1}$, Magdalena Kistler ${ }^{2}$, Anne Kasper Giebl ${ }^{2}$, Sylwia Socha ${ }^{1}$, Egon Erwin \\ Rosenberg ${ }^{2}$ and Janusz Gołaś ${ }^{1}$ \\ ${ }^{1}$ AGH University of Science and Technology, Faculty of Energy and Fuels, Al. Mickiewicza 30, 30-059 Kraków, Poland \\ ${ }^{2}$ Institute of Chemical Technologies and Analytics, Vienna University of Technology, Getreidemarkt 9/164, 1060 Vienna, Austria
}

\begin{abstract}
Polycyclic Aromatic Hydrocarbons (PAHs), their nitro-derivatives (NPAHs) and hundreds of other organic compounds are present in ambient air in gas and particulate form. PAHs and NPAHs originate from diesel and gasoline exhaust emission and other combustion sources. NPAHs are also formed through the nitration of parent PAHs in the atmosphere. Concentrations of PAHs and NPAHs in the particulate matter fraction PM10 collected in the centre of Kraków (27.01.2014 - 17.02.2014) were investigated. The thirteen PAHs and four NPAHs: fluorene, phenanthrene, anthracene, fluoranthene, pyrene, benzo[a]anthracene, benzo[a]pyrene, chrysene, benzo[b]fluoranthene, benzo[k]fluoranthene, indeno[1,2,3-c,d]pyrene, benzo[g,h,i]perylene, dibenz[a,h]anthracene, 2-nitrofluorene, 9-nitroanthracene, 3-nitrofluoranthene and 1-nitropyrene were extracted from particulate matter and analysed applying the GC/MS technique. Depending on the compounds the relative recoveries ranged from 72 to $94 \%$. The concentrations of PM10 in the study period ranged between 23.5 and $153.8 \mu \mathrm{g} \cdot \mathrm{m}^{-3}$. The average concentrations of PAHs and NPAHs ranged from 26.6 to $276.4 \mathrm{ng} \cdot \mathrm{m}^{-3}$ and from 0.6 to $9.1 \mathrm{ng} \cdot \mathrm{m}^{-3}$, respectively. The highest concentrations were observed for benzo[a]pyrene, benzo[a]anthracene, pyrene and fluoranthene. The average concentration of benzo[a]pyrene $(\mathrm{BaP})$, which is a marker for the particle-bound atmospheric PAHs, was $9.5 \mathrm{ng} \cdot \mathrm{m}^{-3}$. The concentrations of 3 -nitrofluoranthene and 1-nitropyrene were below the quantification limits of the method $(<\mathrm{MQL})$.
\end{abstract}

\section{Introduction}

Polycyclic aromatic hydrocarbons (PAHs) and their nitrated derivatives (NPAHs) are common organic compounds occurring in the atmosphere both in vapour phase (low molecular weight compounds) and in particulate-bound form (high molecular weight) $[1,2]$. This group of compounds consists of numerous organic compounds with fused benzene rings. Due to their high toxicity, mutagenic and carcinogenic properties PAHs and NPAHs are of great concern to scientists [3-5]. These chemicals are generated as byproducts of the incomplete combustion of fuels like coal, wood, gas and oil. Beside that the mobile sources and open burning affect the increase of PAHs concentration in ambient air [6, 7]. At urban and industrial areas polycyclic aromatic hydrocarbons are almost entirely generated within the anthropogenic activities [8]. NPAHs are derived during the two-step reaction including: (a) the addition of an $\mathrm{OH}$ or $\mathrm{NO}_{2}$ radical at position 1 of the parent $\mathrm{PAH}$, followed by (b) a further $\mathrm{NO}_{2}$ attack (onto position 2 and loss of water or nitric acid, leading to nitration in the 2-position [9]. This reaction can only occur in the gas phase and is rapidly followed by adsorption of NPAH products onto suspended particles [10].
The determination of environmental concentrations of polycyclic aromatic hydrocarbons and their nitrosubstitutes seems to be significant especially in areas where increasing atmospheric pollution is reported. Kraków agglomeration, due to the high traffic intensity and the presence of still developing industrial sites, is highly affected by emission of PAHs and NPAHs. The average concentration of benzo[a]pyrene between 2008 and 2013 in Malopolska Voivodship was $8.4 \mathrm{ng} \cdot \mathrm{m}^{-3}$ [11], whereas the limit value of the $\mathrm{BaP}$ was established on the level of $1 \mathrm{ng} \cdot \mathrm{m}^{-3}$ [12]. This situation encouraged the authors of this paper to investigate the amounts of PAHs and their nitrated derivatives in PM10 samples collected during the heating season in Kraków.

\section{Materials and methods}

\subsection{Materials}

The molecular formulae, physical and chemical properties of the compounds are summarized in Table 1. The parent polycyclic aromatic hydrocarbons (purity in brackets): acenaphtene (99.9\%), acenaphtylene (99.7 $\%)$, anthracene $(99.4 \%)$, benzo[a]anthracene $(98.9 \%)$, benzo[a]pyrene (99.2\%), benzo[b]fluoranthene $(99.9 \%)$, benzo[ghi]perylene (99.6\%), benzo[k]fluoranthene $(99.5$ $\%$ ), chrysene $(99.9 \%)$, dibenzo[a,h]anthracene $(99.9 \%)$,

\footnotetext{
${ }^{a}$ Corresponding author: styszko@agh.edu.pl
} 
phenanthrene (99.1\%), fluoranthene (99.7\%), fluorene (99.6\%), indeno[1,2,3-cd]pyrene (99.9\%), naphthalene $(99.4 \%)$, pyrene $(96.6 \%)$ used in this study were supplied by Sigma-Aldrich. 1-bromopentadecane (BrPD, $>97 \%$ ) and the deuterium-labelled benzo[a]pyrene-d12 (d12-BaP, 98\%) used as an internal and a surrogate standard, respectively, were acquired from Sigma-

Table 1. Characteristics of analytes.
Aldrich. Nitro-substituted polycyclic aromatic hydrocarbons (NPAHs), 2-nitrofluorene (98\%), 9-nitroanthracene (97\%), 3-nitrofluoranthene (90\%) and 1-nitropyrene $(99 \%)$ were supplied by SigmaAldrich. Cyclohexane (99.8\%) was purchased from Merck.

\begin{tabular}{|c|c|c|c|c|}
\hline Compound & Structure & $\begin{array}{c}\text { Molar mass } \\
{\left[\mathrm{g} \cdot \mathrm{mol}^{-1}\right]}\end{array}$ & $\begin{array}{c}\text { Boiling point } \\
{\left[{ }^{\circ} \mathrm{C}\right]} \\
\end{array}$ & $\begin{array}{c}\text { Solubility in water } \\
{\left[\mu \mathrm{g} \cdot \mathrm{L}^{-1}\right]}\end{array}$ \\
\hline \multicolumn{5}{|c|}{ Parent polycyclic aromatic hydrocarbons, PAHs } \\
\hline naphthalene & & 128 & 218 & 31000.0 \\
\hline acenaphthene & & 154 & 279 & 3900.0 \\
\hline acenaphthylene & & 152 & 265 & 16100.0 \\
\hline fluorene & & 166 & 295 & 1890.0 \\
\hline anthracene & & 178 & 340 & 43.4 \\
\hline phenanthrene & & 178 & 340 & 1150.0 \\
\hline fluoranthene & & 202 & 384 & 260.0 \\
\hline pyrene & & 202 & 404 & 135.0 \\
\hline chrysene & & 228 & 448 & 2.0 \\
\hline benzo[a]anthracene & & 228 & 438 & - \\
\hline benzo[a]pyrene & & 228 & 438 & 9.4 \\
\hline benzo[b]fluoranthene & & 252 & 481 & 1.5 \\
\hline benzo[k]fluoranthene & & 252 & 480 & 0.006 \\
\hline dibenzo[a,h]anthracene & & 278 & 524 & 02.5 \\
\hline benzo[ghi]perylene & & 276 & 550 & 0.3 \\
\hline indeno[1,2,3-cd]pyrene & & 276 & 536 & 0.6 \\
\hline \multicolumn{5}{|c|}{ Nitro-substituted polycyclic aromatic hydrocarbons, NPAHs } \\
\hline 2-nitrofluorene & & 211 & 374 & less than 1000.0 \\
\hline 9-nitroanthracene & & 223 & 275 & less than 100.0 \\
\hline 3-nitrofluoranthene & & 247 & 445 & Insoluble \\
\hline 1-nitropyrene & & 247 & 472 & 11.8 \\
\hline
\end{tabular}




\subsection{Sampling}

The sampling site presented in Figure 1 was located in the centre of Kraków (5004'01.91" N; 1954'45.60" E), the second largest city of Poland (near 1 million inhabitants) which faces serious problems of air pollution. Kraków, located in Southern Poland, is an agglomeration with a high intensity of transport, a power plant, a steel metallurgic factory and some small and medium-size industrial factories. During the heating season the, so called, low-stack emission (mainly domestic heating units (DHUs) using hard coal) significantly contributed to the emission sources balance. Sampling site is a built-up area and represents a typical urban location characterized by high traffic intensity. The measuring location is settled near the green areas as well.

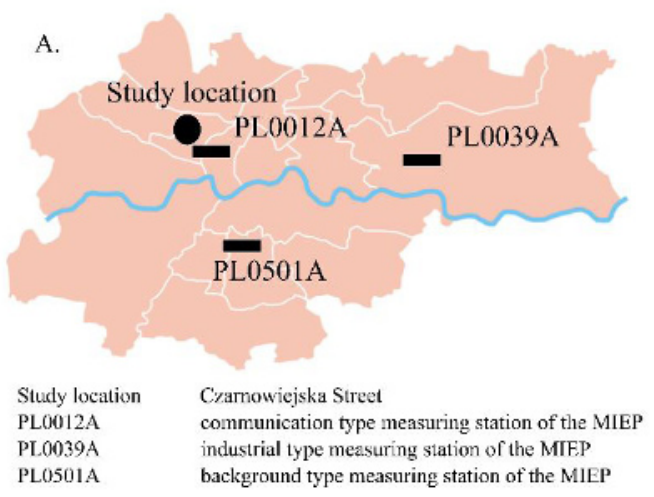

The PM10 fractions were collected during the heating season from January $27^{\text {th }}$ to February $17^{\text {th }}, 2014$ on quartz fiber filters (Pallflex, $47 \mathrm{~mm}$ ) using low volume samplers. Air flow was set up on $2.3 \mathrm{~m}^{3} \cdot \mathrm{h}^{-1}$. In total, the batch of 14 samples of PM10 fraction was collected. All quartz fiber filters had been preheated for $6 \mathrm{~h}$ at 550 $\pm 8{ }^{\circ} \mathrm{C}$ and then maintained at temperature $20 \pm 1{ }^{\circ} \mathrm{C}$ and relative humidity $50 \pm 5 \%$ for at least $24 \mathrm{~h}$ prior to weighting and sampling. After sampling, all filters were conditioned for $48 \mathrm{~h}$, weighted in microbalance (OHAUS Discovery DV215CD) up to accuracy of 0.01 $\mathrm{mg}$ and then stored in a freezer at $-20{ }^{\circ} \mathrm{C}$ until analysis. The masses of the filters before and after sampling were obtained as the average of three measurements. PM10 mass was computed as a difference of mean masses of filters after and before sampling, respectively.

Figure 1. A. Map of the Kraków agglomeration with marked study location and monitoring station of the Malopolska Inspectorate of Environmental Protection; B. PM10 and BaP annual concentrations measured at the station of the Malopolska Inspectorate of Environmental Protection in 2014.

Meteorological data during sampling period were collected from the online platform (http://meteo.ftj.agh.edu.pl/) where the results of the meteorological measurements are directly transferred from the Vaisala WXT520 automatic meteorological

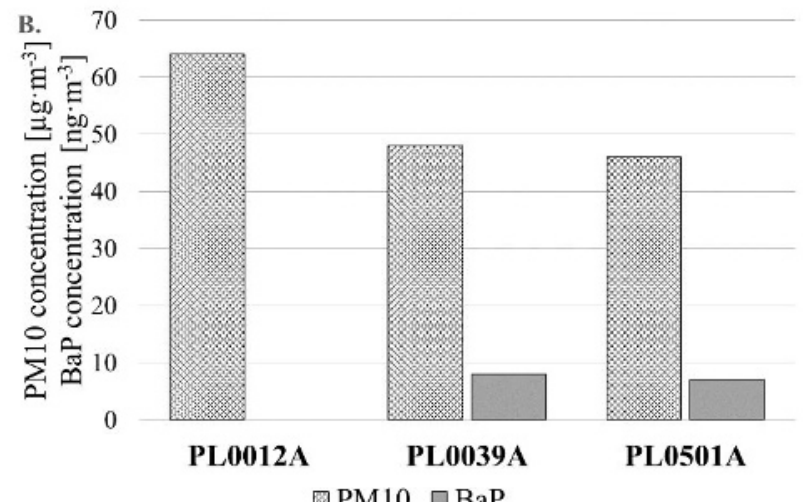

station. The station was placed on the roof of the building where the samples were collected. The details on the meteorological conditions during the study period from Jan $27^{\text {th }}$ to Feb $17^{\text {th }}, 2014$ are summarized in Table 2.

Table 2. Meteorological conditions (diurnal mean values) during the study period in Kraków.

\begin{tabular}{|c|c|c|c|c|c|}
\hline Date & Wind velocity $\left[\mathrm{m} \cdot \mathrm{s}^{-1}\right]$ & Temperature $\left[{ }^{\circ} \mathrm{C}\right]$ & $\begin{array}{c}\text { Relative } \\
\text { humidity [\%] }\end{array}$ & $\begin{array}{l}\text { Precipitation } \\
{[\mathrm{mm}]}\end{array}$ & PM10 $\left[\mu \mathrm{g} \cdot \mathrm{m}^{-3}\right]$ \\
\hline 27.01 .2014 & 2.0 & -8.1 & 73 & 0.01 & 31.7 \\
\hline 28.01 .2014 & 2.9 & -7.7 & 72 & 0 & 25.9 \\
\hline 29.01 .2014 & 3.1 & -6.8 & 71 & 0 & 23.5 \\
\hline 30.01 .2014 & 3.0 & -7.4 & 69 & 0 & 33.0 \\
\hline 03.02 .2014 & 1.0 & -0.1 & 66 & 0 & 136.6 \\
\hline 04.02 .2014 & 0.9 & -0.9 & 60 & 0 & 119.2 \\
\hline 05.02 .2014 & 1.1 & 2.7 & 52 & 0 & 149.6 \\
\hline 06.02 .2014 & 1.2 & 2.3 & 70 & 0 & 52.9 \\
\hline 07.02 .2014 & 1.0 & 3.9 & 65 & 0 & 47.4 \\
\hline 10.02 .2014 & 2.0 & 4.8 & 65 & 0.83 & 113.0 \\
\hline 11.02 .2014 & 1.3 & 6.1 & 69 & 1.27 & 35.6 \\
\hline 12.02 .2014 & 1.5 & 3.2 & 79 & 3.16 & 49.2 \\
\hline 13.02 .2014 & 1.0 & 1.2 & 82 & 0 & 79.9 \\
\hline 14.02 .2014 & 1.7 & 3.2 & 71 & 0.18 & 51.8 \\
\hline 17.02 .2014 & 1.4 & 5.8 & 60 & 0 & 97.2 \\
\hline Mean & 1.7 & -0.2 & 68 & 0.34 & 69.8 \\
\hline Ranges & $0.9-3.1$ & $(-8.1-6.1)$ & $(52-81)$ & $(0.00-3.16)$ & $(23.5-149.6)$ \\
\hline
\end{tabular}

\footnotetext{
a Corresponding author: styszko@agh.edu.pl
} 


\subsection{Chemical analysis of carbon species}

The thermo-optical method (Sunset Lab OC/EC Aerosol Analyser, Sunset Lab. Inc.) was applied for the determination of the organic (OC) and elemental (EC) carbon concentrations in PM samples using the Eusaar2 temperature protocol [13]. Inorganic ions concentration was determined by suppressed isocratic ion chromatography with conductometric detection (Thermo Scientific). For the purpose of the analysis of ion concentrations and the amount of carbonaceous components in PM10, the circular aliquots $(10 \mathrm{~mm} \varnothing)$ were cut out from the filters using a steel puncher and dissolved in high purity water (Milli-Q) or methan sulfonic acid (MSA). The details of the analytical procedures are presented in the previous work [14].

\subsection{Analysis of PAHs and NPAHs}

The concentration of PAHs in particulate matter was determined using gas chromatography coupled with mass spectrometry (Shimadzu QP2010 Ultra GC/MS system equipped with an AOC-5000 autosampler (both Shimadzu, Kyoto)). Concentrations were determined for a total number of 16 PAHs and 4 NPAHs (Table 1).

Table 3. Chromatographic and mass spectrometric characterization of analytes: RT - retention time, mass of characteristic ions, calibration range, correlation coefficients $\left(\mathrm{R}^{2}\right)$.

\begin{tabular}{|c|c|c|c|c|c|}
\hline Compound & $\begin{array}{l}\text { Retention time } \\
{[\text { min] }}\end{array}$ & Ions $\mathbf{m} / \mathbf{z}$ & $\begin{array}{c}\text { Range of concentration } \\
{\left[\mu \mathrm{g} \cdot \mathrm{mL}^{-1}\right]}\end{array}$ & $\mathbf{R}^{2}$ & $\begin{array}{l}\text { MQL } \\
{\left[\mathbf{n g} \cdot \mathbf{m}^{-3}\right]}\end{array}$ \\
\hline Fluorene & 11,870 & 166,139 & $1-7$ & 0.9983 & 0.18 \\
\hline Phenanthrene & 13,057 & 178,152 & \multirow{2}{*}{$0.5-3.5$} & 0.9988 & 0.07 \\
\hline Anthracene & 13,112 & 178,152 & & 0.9989 & 0.07 \\
\hline Fluoranthene & 14,532 & 202,101 & $1-7$ & 0.9984 & 0.11 \\
\hline Pyrene & 14,820 & 202,101 & \multirow{3}{*}{$0.5-3.5$} & 0.999 & 0.05 \\
\hline Benzo[a]anthracene & 16,758 & 228,114 & & 0.9992 & 0.04 \\
\hline Chrysene & 16,848 & 228,114 & & 0.9991 & 0.05 \\
\hline Benzo[b]fluoranthene & 19,687 & 252,126 & $1-7$ & 0.9989 & 0.11 \\
\hline Benzo[k]fluoranthene & 19,748 & 252,126 & \multirow{3}{*}{$0.5-3.5$} & 0.9993 & 0.04 \\
\hline Benzo[a]pyrene & 20,582 & 252,126 & & 0.9993 & 0.04 \\
\hline Indeno[1,2,3-cd]pyrene & 24,087 & 276,138 & & 0.9988 & 0.05 \\
\hline Dibenzo[a,h]anthracene & 24,188 & 278,139 & \multirow{2}{*}{$1-7$} & 0.9991 & 0.09 \\
\hline Benzo[g,h,i]perylene & 25,108 & 276,138 & & 0.9994 & 0.07 \\
\hline 2-nitrofluorene & 14,732 & 165,211 & \multirow{4}{*}{$1-10$} & 0.9947 & 0.09 \\
\hline 9-nitroanthracene & 14,912 & 223,193 & & 0.9942 & 0.11 \\
\hline 3-nitrofluoranthene & 17,510 & 247,217 & & 0.9904 & 0.11 \\
\hline 1-nitropyrene & 18,057 & 247,201 & & 0.9917 & 0.09 \\
\hline 1-bromopentadecan & 13,248 & 43,57 & \multirow{2}{*}{$1-10$} & 0.9947 & - \\
\hline Benzo[a]pyrene- $d_{12}$ & 20,520 & 264,132 & & 0.9942 & - \\
\hline
\end{tabular}

Two circular aliquots $(10 \mathrm{~mm} \varnothing)$ per filter were punched. Aliquots of two up to four filters were compiled to obtain a mass of sample above $1 \mathrm{mg}$. The PAHs and NPAHs concentrations were computed according to the PM mass ratio of each sample. The filter aliquots were placed in a glass tube $(10 \mathrm{~mL})$ and spiked with $50 \mu \mathrm{L}(10$ $\mathrm{ng} \cdot \mu \mathrm{L}^{-1}$ ) solution of d12-benzo[a]pyrene (d12-BaP). After $20 \mathrm{~min}$, the analytes were ultrasonically extracted from the sample twice with $5 \mathrm{~mL}$ of cyclohexane for 20 minutes. The combined extracts were spiked with $50 \mu \mathrm{L}$ (10 $\left.\mathrm{ng} \cdot \mu \mathrm{L}^{-1}\right)$ solution of bromopentadecane (BrPD). The volume of the extract was reduced to $250 \mu \mathrm{L}$ using a gentle stream of nitrogen in a multiport condenser at $35{ }^{\circ} \mathrm{C}$ for about $35 \mathrm{~min}$. The concentrate was successively transferred into $2 \mathrm{~mL}$ chromatographic vial equipped with $300 \mu \mathrm{L}$ insert for analysis by GC/MS.

The PAHs $\left(200 \mu \mathrm{g} \cdot \mathrm{mL}^{-1}\right)$ and NPAHs $\left(50 \mu \mathrm{g} \cdot \mathrm{mL}^{-1}\right)$ stock solutions were kept in a fridge at $4{ }^{\circ} \mathrm{C}$. The stock solutions served for preparation of calibrations standards with the concentration range from 0.5 to $10 \mu \mathrm{g} \cdot \mathrm{mL}^{-1}$ (see Table 3). Standard solutions were diluted in cyclohexane with an addition of $200 \mathrm{ng} \cdot \mathrm{mL}^{-1}$ of the internal standard.

The chromatographic separation of target analytes was performed with a DB5MS capillary column $(30 \mathrm{~m} \mathrm{x}$ $0.25 \mathrm{~mm}$ i.d. $\mathrm{x} 0.25 \mu \mathrm{m}$ film thickness) with $1.2 \mathrm{~mL} \cdot \mathrm{min}^{-1}$ helium (quality $99.999+\%$ ) as a carrier gas. The oven temperature program was as follows: isothermal hold at $70{ }^{\circ} \mathrm{C}$ for $4 \mathrm{~min}$, temperature ramp of $20{ }^{\circ} \mathrm{C} \cdot \mathrm{min}^{-1}$ to $280^{\circ} \mathrm{C}$ and then $20^{\circ} \mathrm{C} \cdot \mathrm{min}^{-1}$ to $300^{\circ} \mathrm{C}$, isothermal hold at $300{ }^{\circ} \mathrm{C}$ for $5 \mathrm{~min}$. Injection was performed with a split/splitless injector at a temperature of $320{ }^{\circ} \mathrm{C}$. Splitless time was set to $1 \mathrm{~min}$ and injection volume to $2 \mu \mathrm{L}$. The $\mathrm{GC} / \mathrm{MS}$ interface temperature and ion source were kept at $250{ }^{\circ} \mathrm{C}$ and $200^{\circ} \mathrm{C}$, respectively.

Detection was performed with a quadrupole mass spectrometer operated in the positive electron impact 
mode at $70 \mathrm{eV}$. The mass spectra were obtained in the total ion current (TIC) mode over a mass range $(\mathrm{m} / \mathrm{z})$ of $50-500 \mathrm{amu}$ and in the single ion monitoring (SIM) mode. Identification of the target compounds in the analysed samples was based on the retention time, quantitative ion and confirmation ion. Quantitative analysis was based on the peak areas of the quantitative ions recorded in the SIM mode. Each GC analysis was repeated at least two times. The retention times, characteristic ions of all analytes and validation parameters of the method are shown in Table 3.

The proposed method was validated using a calibration with standard solutions. Filter blanks were also extracted and analysed in the same way as field samples. Target compounds were not detectable in the blanks. The method quantification limit (MQL) was evaluated on the base of analyses on blank samples, with signal-to-noise ratio of 10:1. The concentrations of the compounds in the ambient air were corrected using the recovery percentages. Recovery efficiencies were determined by evaluating the surrogate standard in the samples. Recovery of surrogate standard was $94 \%$.

\section{Results and discussion}

The gravimetrically measured PM10 concentration during the study period equalled $69.8 \pm 42.7 \mu \mathrm{g} \cdot \mathrm{m}^{-3}$ on average, varying from 23.5 to $149.6 \mu \mathrm{g} \cdot \mathrm{m}^{-3}$. The daily maximum value for PM10 in ambient air, set up within the European Commission directive 2008/50/CE $\left(50 \mu \mathrm{g} \cdot \mathrm{m}^{-3}\right)$, was exceeded nine times during the 15 -days study period. The highest concentrations of PM10 were reported on Feb $3^{\text {rd }}\left(136.6 \mu \mathrm{g} \cdot \mathrm{m}^{-3}\right)$, Feb $4^{\text {th }}\left(153.8 \mu \mathrm{g} \cdot \mathrm{m}^{-3}\right)$ and Feb $6^{\text {th }}\left(112.9 \mu \mathrm{g} \cdot \mathrm{m}^{-3}\right)$. In this period the diurnal mean ambient temperature varied between -0.9 and $2.7{ }^{\circ} \mathrm{C}$, wind velocity between 0.87 and $1.18 \mathrm{~m} \cdot \mathrm{s}^{-1}$, relative humidity between 52 and $70 \%$. The lowest concentration of PM10 was noted at the beginning of the study period and equalled $23.5 \mu \mathrm{g} \cdot \mathrm{m}^{-3}$. In this period the ambient temperature decreased down to $-8.1{ }^{\circ} \mathrm{C}$ and the wind was blowing with the velocity of $3.1 \mathrm{~m} \cdot \mathrm{s}^{-1}$ on Jan $29^{\text {th }}$. PAHs and NPAHs exhibited similar patterns as PM10. The highest concentrations of examined PAHs and NPAHs were reported on Feb $3^{\text {rd }}, 4^{\text {th }}$ and $6^{\text {th }}$ when the sum of analytes concentrations was equal to $386.4 \mathrm{ng} \cdot \mathrm{m}^{-3}, 428.1 \mathrm{ng} \cdot \mathrm{m}^{-3}, 408.8 \mathrm{ng} \cdot \mathrm{m}^{-3}$, respectively for PAHs and $26.3 \mathrm{ng} \cdot \mathrm{m}^{-3}, 18.2 \mathrm{ng} \cdot \mathrm{m}^{-3}, 27.5 \mathrm{ng} \cdot \mathrm{m}^{-3}$, respectively for NPAHs (Figure 2). Low temperature conditions are favourable for the condensation of the organic compounds and the sorption of the surface of particulate matter. However, higher wind velocities, as it was noted at the beginning of February in Kraków, caused the removal of particulates-bound organic compounds resulting in lower concentrations of PAHs and NPAHs in later part of February.

The presence of two, among four, nitro-compounds was detected in measured PM10 samples. Table 4 presents the mean concentrations of analysed PAHs and NPAHs in ambient air during the study period in Kraków.

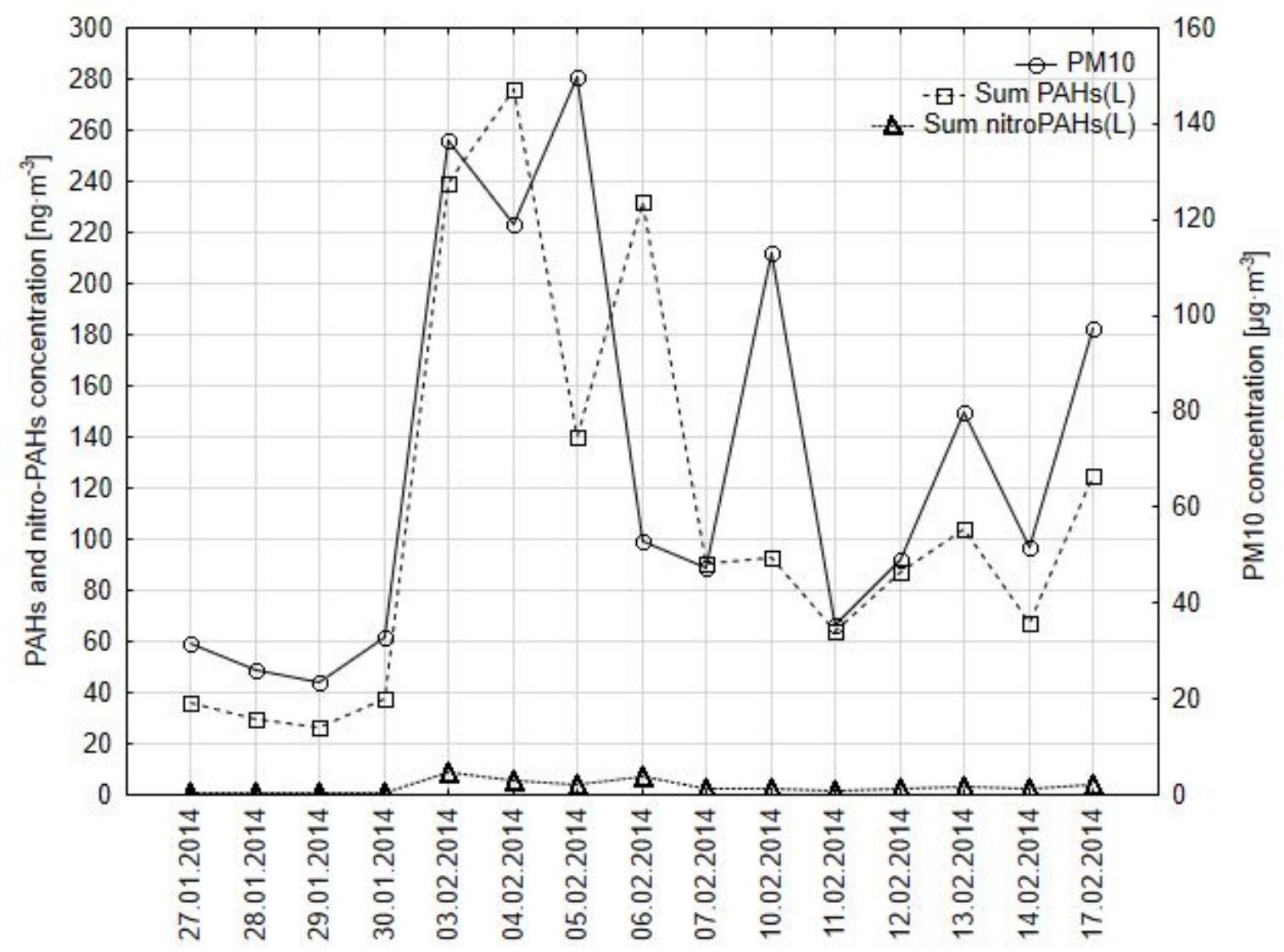

Figure 2. Variation of the sum of PAHs (open squares) concentration, NPAHs concentration (open triangles) and PM10 concentration (open circles) during the study period. 
Fluoranthene, pyrene, benzo[a]anthracene and chrysene exhibited the highest concentrations in the ambient air among all analysed PAHs ranging between 4.7 and $46.1 \mathrm{ng} \cdot \mathrm{m}^{-3}$ for fluoranthene, between 4.1 and $40.5 \mathrm{ng} \cdot \mathrm{m}^{-3}$ for pyrene, between 3.0 and $33.8 \mathrm{ng} \cdot \mathrm{m}^{-3}$ for benzo[a]anthracene, between 3.1 and $31.5 \mathrm{ng} \cdot \mathrm{m}^{-3}$ for chrysene. In turn, the lowest amounts were reported for flourene and phenanthrene. This may be affected either by the specific emission sources (mostly traffic) from which the PAHs are derived, stable atmospheric conditions which favour the particle concentrations [15], PAHs tendency to sorb onto the surface of particulates at lower temperatures [8], photochemical degradation of PAHs due to ozone and $\mathrm{NO}_{\mathrm{x}}$ reactions [16], and lower ability to evaporate of PAHs with higher values of molecular weight of PAHs. Moreover, PAHs which have least than 5 rings occur both in gas and particle bound phase. Results presented in the paper refer to the particle-bound phase what is the reason of low concentrations of fluorine, phenanthrene or anthracene. High molecular weight PAHs are more often associated with atmospheric particulate matter than low molecular weight PAHs which are vapour-phase components [2]. 2-nitrofluorene exhibited the highest mean concentration $\left(2.2 \pm 1.7 \mathrm{ng} \cdot \mathrm{m}^{-3}\right)$ among all examined nitrated derivatives of PAHs ranging between 0.5 and $5.6 \mathrm{ng} \cdot \mathrm{m}^{-3}$. The concentration of 9-nitroanthracene was equal to $0.9 \mathrm{ng} \cdot \mathrm{m}^{-3}$, on average. The obtained concentrations of 2-nitrofluorene and 9-nitroanthracene in Kraków were reported on the same level of magnitude as in another industrial cities in Poland: in Katowice and Sosnowiec [17]. In Katowice the mean concentrations were equal to 1.7 and $2.6 \mathrm{ng} \cdot \mathrm{m}^{-3}$, and in Sosnowiec -1.8 and 2.4 $\mathrm{ng} \cdot \mathrm{m}^{-3}$, respectively. In Kraków, during the heating season PAHs and NPAHs, especially chrysene, benzo[a]pyrene or 9-nitroanthracene, are mainly emitted during the combustion of coal, wastes or biomass in domestic stoves $[18,19]$. Traffic-related pollutions are another factor which influence the increase of these organic compounds amount. The samples of PM10 were collected near the streets with high intensity of transport what could have an impact on the augmentation of PAHs like: benzo[a]pyrene, benzo[b]fluoranthene, benzo[k]fluoranthene, benzo[ghi]perylene and fluoranthene. Emission of exhausts from diesel engines is considered as a main source of 2-nitrofluorene [20-22].

Table 4. Mean concentrations $\left(\mathrm{ng} \cdot \mathrm{m}^{-3}\right.$ ) of PAHs and NPAHs bound to PM10 fraction during the study period.

\begin{tabular}{|l|c|l|c|}
\hline Compound & $\begin{array}{c}\text { Mean concentration } \\
{\left[\mathbf{n g} \cdot \mathbf{m}^{-3}\right]}\end{array}$ & Compound & $\begin{array}{c}\text { Mean concentration } \\
{\left[\mathbf{n g} \cdot \mathbf{m}^{-3}\right]}\end{array}$ \\
\hline Fluorene & $0.2 \pm 0.4$ & Benzo[k]fluoranthene & $9.3 \pm 6.7$ \\
Phenanthrene & $5.7 \pm 4.4$ & Benzo[a]pyrene & $9.5 \pm 7.0$ \\
Anthracene & $1.5 \pm 1.2$ & Indeno[1,2,3cd]pyrene & $7.0 \pm 5.0$ \\
Fluoranthene & $17.2 \pm 12.8$ & Dibenzo[a,h]anthracene & $1.2 \pm 0.9$ \\
Pyrene & $15.4 \pm 11.3$ & Benzo[g,h,i]perylene & $6.0 \pm 4.3$ \\
Benzo[a]anthracene & $14.1 \pm 10.3$ & 2-nitrofluorene & $2.2 \pm 1.6$ \\
Chrysene & $13.5 \pm 9.8$ & 9-nitroanthracene & $0.9 \pm 0.9$ \\
Benzo[b]fluoranthene & $9.5 \pm 6.8$ & & \\
\hline
\end{tabular}

The daily concentration limit value of the main atmospheric pollution indicator. BaP, $\left(1 \mathrm{ng} \cdot \mathrm{m}^{-3}\right)$ was exceeded during the entire 15-days study period. Its average concentration was equal to $9.5 \pm 7.0 \mathrm{ng} \cdot \mathrm{m}^{-3}$, and ranged between $2.0 \mathrm{ng} \cdot \mathrm{m}^{-3}$ on $\mathrm{Jan} 29^{\text {th }}$ and 23.1 $\mathrm{ng} \cdot \mathrm{m}^{-3}$ on Feb $4^{\text {th }}$. The highest concentration of $\mathrm{BaP}$ was observed at the beginning of February when in period Feb $3^{\text {rd }}-6^{\text {th }}$ the mean concentration of $\mathrm{BaP}$ equalled to $19.2 \mathrm{ng} \cdot \mathrm{m}^{-3}$. In Figure 1 the annual for 2014 concentrations of $\mathrm{BaP}$ for two measuring stations belonging to the Malopolska Inspectorate of Environment Protection are showed. $\mathrm{BaP}$ amount was equal to $8 \mathrm{ng} \cdot \mathrm{m}^{-3}$ and $7 \mathrm{ng} \cdot \mathrm{m}^{-3}$ at the industrial type and background type stations in Kraków, respectively. These concentrations are at the similar level as the $\mathrm{BaP}$ amount measured by authors of this study, however this paper refers to the short 15-days study period. While comparing the mean concentration of other PAHs it may be noticed that in all cases the annual limit value for $\mathrm{BaP}$ was exceeded.

\section{Conclusions}

Experiments on the assessment of the level of ambient air pollution by airborne particulates-bounded polycyclic aromatic hydrocarbons and NPAHs showed the high concentration of these compounds during the study period. The measurements proved the presence of all examined PAHs and two, among the investigated four, NPAHs. The lowest concentration was reported for fluorene, the highest - for fluoranthene. Among analysed NPAHs, 2-fluorene demonstrated the highest amounts. As the samples of PM were collected in Kraków near the areas of high traffic intensity, the obtained concentrations of 2-nitrofluorene were significantly higher than in Katowice or Sosnowiec, which are mainly polluted by emission from the large-scale coal industry. The, so called, low-stack emission, traffic-related pollution and industrial activities are considered to be main emitters of PAHs and NPAHs in Kraków. Additionally, favourable meteorological conditions, specially low temperature, low wind velocity and low relative humidity force the accumulation of organic compounds and sorption on the particulate matter surface.

The identification of emission sources of air pollutants is very important for the assessment and management of air quality of a determined region. This creates possibilities for further work of the authors.

\section{Acknowledgements}

This work was partially supported by AGH University Grant no 11.11.210.244 and by the Rector's Grant for the 
AGH Student Association RedoX. The authors acknowledge the financial support of OeaD and of the Ministry of Science and Higher Education (Poland) in the frame of project WTZ (Wissenschaftlich-Technische Zusammenarbeit), No. PL09/2015.

\section{References}

1. D.M. Agudelo-Castañeda, E.C. Teixeira, Atmos. Environ. 96 (2014).

2. X. Bi, G. Sheng, P.a. Peng, Y. Chen, Z. Zhang, J. Fu, Atmos. Environ. 37,2 (2003).

3. K.-H. Kim, S.A. Jahan, E. Kabir, R.J.C. Brown, Environ. Int. 60 (2013).

4. A.J. Grosovsky, J.C. Sasaki, J. Arey, D.A. Eastmond, K.K. Parks, R. Atkinson, Res. Rep. Health Eff. Inst.,84 (1999).

5. H.I. Abdel-Shafy, M.S.M. Mansour, Egyptian Journal of Petroleum 25,1 (2016).

6. M. Li, S.R. McDow, D.J. Tollerud, M.A. Mazurek, Atmos. Environ. 40,13 (2006).

7. E.C. Teixeira, D.M. Agudelo-Castañeda, C.D.P. Mattiuzi, Sci. Total Environ. 538 (2015).

8. K. Ravindra, L. Bencs, E. Wauters, J. de Hoog, F. Deutsch, E. Roekens, N. Bleux, P. Berghmans, R. Van Grieken, Atmos. Environ. 40,4 (2006).

9. J.N. Pitts, J.A. Sweetman, B. Zielinska, A.M. Winer, R. Atkinson, Atmospheric Environment (1967) 19,10 (1985).

10. R. Atkinson, J. Arey, B. Zielinska, S.M. Aschmann, Int. J. Chem. Kinet. 22,9 (1990).

11. http://monitoring.Kraków.pios.gov.pl/. [accessed: May 15th 2016].

12. Directive 2004/107/EC of the European Parliament and of the Council of 15 December 2004 relating to arsenic, cadmium, mercury, nickel and polycyclic aromatic hydrocarbons in ambient air

13. F. Cavalli, M. Viana, K.E. Yttri, J. Genberg, J.P. Putaud, Atmos. Meas. Tech. 3,1 (2010).

14. K. Styszko, K. Szramowiat, M. Kistler, A. Kasper-Giebl, L. Samek, L. Furman, J. Pacyna, J. Gołaś, Comptes Rendus Chimie 18,10 (2015).

15. P. Di Filippo, C. Riccardi, D. Pomata, F. Buiarelli, Atmos. Environ. 44,23 (2010).

16. R. Chirico, P. Spezzano, D. Cataldi, Polycyclic Aromat. Compd. 27,5 (2007).

17. M. Zaciera, J. Kurek, L. Dzwonek, B. Feist, A. Jędrzejczak, Environment protection Engineering 38,1 (2012).

18. G. Shen, S. Tao, S. Wei, Y. Zhang, R. Wang, B. Wang, W. Li, H. Shen, Y. Huang, Y. Chen, H. Chen, Y. Yang, W. Wang, X. Wang, W. Liu, S.L.M. Simonich, Environ. Sci. Technol. 46,15 (2012).

19. G. Shen, S. Tao, Y. Chen, Y. Zhang, S. Wei, M. Xue, B. Wang, R. Wang, Y. Lv, W. Li, H. Shen, Y. Huang, H. Chen, Environ. Sci. Technol. 47,24 (2013).

20. J. Ringuet, E. Leoz-Garziandia, H. Budzinski, E. Villenave, A. Albinet, Atmos. Chem. Phys. 12,18 (2012).
21. W. Wang, N. Jariyasopit, J. Schrlau, Y. Jia, S.H.U. Tao, T.-W. Yu, R.H. Dashwood, W.E.I. Zhang, X. Wang, S.L.M. Simonich, Environ. Sci. Technol. 45,16 (2011).

22. I. Zwirner-Baier, H.G. Neumann, Mutat Res 441,1 (1999). 